\title{
Effect of repeated Waon therapy on exercise tolerance and pulmonary function in patients with chronic obstructive pulmonary disease: a pilot controlled clinical trial
}

\author{
This article was published in the following Dove Press journal: \\ International Journal of COPD \\ II December 2013 \\ Number of times this article has been viewed
}

\author{
Hiroshi Kikuchi',2 \\ Nobuyoshi Shiozawa' \\ Shingo Takata' \\ Kozo Ashida' \\ Fumihiro Mitsunobu' \\ 'Division of Medicine, Misasa Medical \\ Center, Okayama University Hospital, \\ Misasa, Tottori, Japan; ${ }^{2}$ Division of \\ Internal Medicine, Takamatsu Hospital \\ KKR, Takamatsu, Japan
}

\begin{abstract}
Purpose: Controlled clinical trials evaluating the efficacy of repeated Waon therapy for patients with chronic obstructive pulmonary disease (COPD) have yet to be conducted. The purpose of the present study was to evaluate whether repeated Waon therapy exhibits an adjuvant effect on conventional therapy for COPD patients.

Patients and methods: This prospective trial comprised 20 consecutive COPD patients who satisfied the criteria of the Global initiative for chronic Obstructive Lung Disease (GOLD) guidelines, stages 1-4. They were assigned to either a Waon or control group. The patients in the Waon group received both repeated Waon therapy and conventional therapy, including medications, such as long-acting inhaled $\beta 2$ agonists, long-acting anticholinergics and xanthine derivatives, and pulmonary rehabilitation. The Waon therapy consisted of sitting in a $60^{\circ} \mathrm{C}$ sauna room for 15 minutes, followed by 30 minutes of being warmed with blankets once a day, 5 days a week, for a total of 20 times. The patients in the control group received only conventional therapy. Pulmonary function and the 6-minute walk test were assessed before and at 4 weeks after the program.

Results: The change in vital capacity $(0.30 \pm 0.4 \mathrm{~L})$ and in peak expiratory flow $(0.48 \pm 0.79 \mathrm{~L} / \mathrm{s})$ in the Waon group was larger than the change in the vital capacity $(0.02 \pm 0.21 \mathrm{~L})(P=0.077)$ and peak expiratory flow $(-0.11 \pm 0.72 \mathrm{~L} / \mathrm{s})(P=0.095)$ in the control group. The change in forced expiratory flow after $50 \%$ of expired forced vital capacity in the Waon group, $0.08(0.01-0.212 \mathrm{~L} / \mathrm{s})$, was larger than that in the control group, $-0.01(-0.075-0.04 \mathrm{~L} / \mathrm{s})(P=0.019)$. Significant differences were not observed in the change in any parameters in the 6-minute walk test. Data are presented as means \pm standard deviation or median (25th-75th percentile).
\end{abstract}

Conclusion: The addition of repeated Waon therapy to conventional therapy for COPD patients can possibly improve airway obstruction.

Keywords: modified Borg scale, airway obstruction, 6-minute walk test, quality of life

\section{Introduction}

The number of patients diagnosed with chronic obstructive pulmonary disease (COPD) has been gradually increasing in Japan as the population ages. As various kinds of drugs, such as long-acting $\beta 2$ agonists and long-acting anticholinergics, have come into wide use in recent years, the number of COPD patients who can live in a stable condition for many years has increased. However, pulmonary rehabilitation plays an irreplaceable role and is one of the most effective interventions in improving quality of life (QOL), ${ }^{1,2}$ exercise tolerance, and fatigue, for all COPD patients. ${ }^{3}$
Correspondence: Fumihiro Mitsunobu Okayama University Hospital, Misasa Medical Center, 827 Yamada, Misasa,

Tohaku, Tottori 682-0I22, Japan

Tel +8I 85843 |2 II

Fax +8I 858431305

Email fumin@cc.okayama-u.ac.jp 
Especially in clinical practice, the purpose of treatment for COPD patients is to improve certain respiratory symptoms, such as dyspnea on exertion and coughing up of sputum. Improvement of symptoms can expand patients' functional participation in activities of daily living and improve their QOL.

Some studies indicating that pulmonary rehabilitation improves QOL for COPD patients have been reported. Godoy et $\mathrm{al}^{4}$ reported that the benefits provided by a pulmonary rehabilitation program, in terms of the indices of QOL as well as improved 6-minute walk test performance, persisted throughout the 24-month study period, in patients with COPD. Pulmonary rehabilitation does not always need to be conventional. Sindhwani et $\mathrm{al}^{5}$ reported that a domiciliary pulmonary rehabilitation program improved the QOL and exercise endurance of patients with severe COPD and acted as a substitute for conventional pulmonary rehabilitation programs in resource-limited situations. Effective pulmonary rehabilitation for COPD patients is not necessarily formulaic. For example, the study by Rae and White ${ }^{6}$ suggested that the swimming pool was a feasible and positive alternative venue for pulmonary rehabilitation, for COPD patients in primary care. These reports demonstrated that not only medication, but also, nondrug therapy, such as lung physical therapy or exercise therapy, is important for COPD patients and improves their QOL.

Tei et $\mathrm{al}^{7}$ were the first to report on hemodynamic changes in patients with congestive heart failure, during Waon therapy using a far infrared-ray dry sauna which is evenly maintained at $60^{\circ} \mathrm{C}$. Cardiovascular hemodynamics improved after a water bath or sauna, in patients with chronic heart failure due to ischemic or idiopathic dilated cardiomyopathy. Twenty-eight patients showed improvement in left and right ventricular functions, associated with reduction in afterload (total peripheral vascular resistance for the left ventricle and pulmonary vascular resistance for the right ventricle) on thermal vasodilatation after Waon therapy. Warming was also expected to dilate the venous system (which decreases pulmonary congestion). The results indicated that cardiac index, stroke index, peripheral vascular resistance, and pulmonary artery pressure all significantly decreased during and for $30 \mathrm{~min}$ utes after Waon therapy. The duration of the effectiveness of Waon therapy has not been verified yet. Tei et al believed the endothelial nitric oxide synthase (eNOS) upregulation induced by the sauna was caused by increases in the cardiac output and blood flow, which in turn increased the shear stress.

In recent years in Japan, repeated Waon therapy has been put into practical use for patients with heart failure, as a nondrug therapy. Umehara et al reported that repeated Waon therapy improved pulmonary hypertension during exercise, in 13 patients with severe COPD. ${ }^{8}$ They found that the lowest oxygen saturation ( $\mathrm{SpO} 2)$ during exercise, as assessed by ergometer, was significantly elevated and that exercise time was also significantly increased after Waon therapy. We supposed that the improvement of exercise tolerance with COPD after repeated Waon therapy might be associated with an improvement of airway obstruction in addition to improved pulmonary hypertension.

There have been no controlled clinical trials to evaluate the effectiveness of repeated Waon therapy as a nondrug therapy for COPD patients. The purpose of the present study was to evaluate whether repeated Waon therapy could exhibit an added effect to conventional therapies for COPD patients.

\section{Patients and methods}

\section{Patients}

The study population comprised 20 consecutive inpatients and outpatients with COPD (age range 50-80 years) who satisfied the criteria of the Global initiative for chronic Obstructive Lung Disease (GOLD) guidelines for stages 1-4. ${ }^{3}$ Subjects who had suffered from acute exacerbation, leftside heart failure, and who were unable to walk because of arteriosclerosis obliterans or knee osteoarthritis within the month prior to the study were excluded. Subjects who went into respiratory distress and needed to receive additional therapy or who had difficulty walking because of leg pain during the study were also excluded.

\section{Waon therapy}

As previously reported by Tei et al, ${ }^{7}$ a far infrared ray dry sauna; whole body hyperthermia application (dry system) (NOMS Corporation, Aichi, Japan) was used for the Waon therapy. The patients were seated in a $60^{\circ} \mathrm{C}$ sauna room for 15 minutes, and after leaving the sauna, they rested on a bed while covered with a blanket to keep warm, for an additional 30 minutes. The patients were weighed before and after sauna bathing, and oral hydration with water was used to compensate for lost weight. Repeated Waon therapy was performed once a day, 5 days a week (from Monday through Friday), for 4 weeks, for a total of 20 times. ${ }^{8,9}$

\section{Conventional therapy}

For conventional therapy, the subjects were approved to receive medical treatment for $\mathrm{COPD}$, including long-acting $\beta 2$ agonists (LABA), long-acting anticholinergics, xanthine derivatives (oral theophyllines), inhaled glucocorticoids 
(alone or in combination with LABA) and systemic glucocorticoids, and pulmonary rehabilitation, such as walking, swimming training, ergometer exercise, and respiratory training. However new medications and pulmonary rehabilitation programs are assumed to start up to 2 weeks before the study. They have been instructed not to change their program during this study.

\section{Pulmonary function test}

Vital capacity (VC), forced vital capacity (FVC), forced expiratory volume in 1 second $\left(\mathrm{FEV}_{1}\right)$, forced expiratory flow after $50 \%$ of expired $\mathrm{FVC}\left(\mathrm{FEF}_{50}\right)$, forced expiratory flow after $75 \%$ of expired $\mathrm{FVC}\left(\mathrm{FEF}_{25}\right)$, and peak expiratory flow (PEF) were measured in all subjects, using a spirometer (Chestac 33; Chest Co, Tokyo, Japan) linked to a computer.

\section{Exercise tolerance}

The functional status, evaluated as exercise tolerance, was assessed using the 6-minute walk test (6MWT). The $6 \mathrm{MWT}$ followed the pulmonary function test according to a standardized protocol. ${ }^{10}$ It is now the most commonly used timed walking test $\mathrm{t}^{11,12}$ that can predict the risk of death in COPD patients. ${ }^{13,14}$ The distance walked in 6 minutes has been accepted as a good outcome measure after interventions such as pulmonary rehabilitation. ${ }^{15}$ In our study, the 6MWT was carried out in a hospital corridor with a length of $100 \mathrm{~m}$. The subjects were allowed to slow down or stop if needed but were required to resume walking as soon as they felt able. They were given feedback on the elapsed time each minute and were encouraged to continue walking. All subjects were informed of the details of the 6MWT and how it worked. Dyspnea, as measured with the modified Borg dyspnea scale,${ }^{16}$ oxygen saturation, and pulse rate were assessed at the start and end of the 6MWT. Oxygen saturation was measured using a Wrist OxTM (Model 3100; Star Product, Tokyo, Japan).

\section{Study protocol}

The COPD patients were alternately assigned in the enrollment sequence to either the Waon or control group; the former received repeated Waon therapy plus conventional therapy, while the latter received only conventional therapy. The physician explained the study protocol and obtained written informed consent from all participants prior to assigning the patients to the regimen.

The study protocol was approved by the Ethics Committee of the Faculty of Medicine, Okayama University. This clinical trial is registered with the University Hospital
Medical Information Network clinical trials registry (number UMIN000004391).

To rule out any acute effects of Waon therapy, the pulmonary test and 6MWT were performed before the first treatment and on the day after the last treatment. ${ }^{8}$ The outcome measured first was pulmonary function, and then the 6MWT was measured.

\section{Statistical analysis}

All data were expressed as absolute value, means $\pm \mathrm{SD}$, or median (25th-75th percentile). An unpaired $t$-test or Mann-Whitney test was used for comparison between the groups. The statistical analysis was performed using SPSS version 16.0 J for Windows (SPSS Inc, Chicago, IL, USA), and $P$-values $<0.05$ were considered statistically significant.

\section{Results \\ Patients}

Table 1 shows the demographic characteristics, smoking history, degree of severity of respiratory function impairment, and typical therapeutic regimen for COPD patients. No important differences were seen between the two groups, in these characteristics or therapeutic regimens. A total of 20 patients were alternately assigned to each group. Our study program lasted at least 4 weeks, so only two outpatients were able to participate in each group. The study was performed from April 2010 to May 2011, at Misasa Medical Center, Okayama University Hospital, Tottori, Japan.

Table I Baseline demographics of the study groups

\begin{tabular}{lll}
\hline & $\begin{array}{l}\text { Waon } \\
(\mathbf{n = 1 0})\end{array}$ & $\begin{array}{l}\text { Control } \\
(\mathbf{n}=1 \mathbf{0})\end{array}$ \\
\hline Male/female & $9 / 1$ & $9 / 1$ \\
Age, years & $70.3 \pm 5.8$ & $73.6 \pm 6.1$ \\
$\begin{array}{l}\text { Smoking status } \\
\quad \text { Former }\end{array}$ & 10 & 10 \\
$\quad$ Current & 0 & 0 \\
$\quad$ Pack years & $56(27-94)$ & $57(34-103)$ \\
FEV, \% pred & $54.1 \pm 14.7$ & $63.2 \pm 26.6$ \\
Resting SpO,$\%$ & $95.6 \pm 1.8$ & $95.9 \pm 0.7$ \\
Height & $162.4 \pm 5.0$ & $160.4 \pm 4.6$ \\
BMI, kg/m ${ }^{2}$ & $22.3 \pm 2.4$ & $23.0 \pm 2.4$ \\
Medication use & & \\
$\quad$ long-acting anticholinergics & 8 & 6 \\
$\quad$ long-acting $\beta 2$ agonist & 9 & 8 \\
$\quad$ Xanthine derivatives & 7 & 7 \\
Lung physical therapy & 10 & 10 \\
\hline
\end{tabular}

Note: Data are absolute numbers, presented as means \pm SD or median (25th-75th percentile).

Abbreviations: SD, standard deviation; $\mathrm{FEV}_{1}$, forced expiratory volume in second; $\mathrm{SpO}_{2}$, oxygen saturation; $\mathrm{BMI}$, body mass index. 


\section{Exercise tolerance}

All the parameters for the 6MWT are shown in Table 2. A significant between-group difference was not observed in the change in any parameters of the 6MWT.

\section{Pulmonary function}

Table 3 shows the change in ventilator parameters at baseline and after 4 weeks. Figures 1-3 show the changes in VC, PEF, and $\mathrm{FEF}_{50}$, respectively. The change in $\mathrm{VC}(0.30 \pm 0.4 \mathrm{~L})$ in the Waon group was larger than that in the control group $(0.02 \pm 0.21 \mathrm{~L})(P=0.077)$, as shown in Figure 1 . The change in PEF $(0.48 \pm 0.79 \mathrm{~L} / \mathrm{s})$ in the Waon group was larger than that in the control group $(-0.11 \pm 0.72 \mathrm{~L} / \mathrm{s})(P=0.095)$, as shown in Figure 2. A significant between-group difference was observed in the changes in $\mathrm{FEF}_{50}$, which was larger in the Waon group $(0.08 \mathrm{~L} / \mathrm{s}[0.01-0.212 \mathrm{~L} / \mathrm{s}])$ than in the control group $(-0.01 \mathrm{~L} / \mathrm{s}[-0.075-0.04 \mathrm{~L} / \mathrm{s}])(P=0.019)$, as shown in Figure 3. By comparison, there was no significant difference in the change in $\mathrm{FEV}_{1}$ between the Waon group $(0.12 \pm 0.23 \mathrm{~L})$ and the control group $(-0.14 \pm 0.12 \mathrm{~L})$ $(P=0.120)$. There was also no significant difference in the change in FVC between the Waon group $(0.17 \pm 0.44 \mathrm{~L})$ and the control group $(-0.06 \pm 0.37 \mathrm{~L})(P=0.233)$. Furthermore, there was no significant difference in the change in $\mathrm{FEF}_{25}$ between the Waon group $(0.03 \mathrm{~L} / \mathrm{s}[-0.03-0.057$ $\mathrm{L} / \mathrm{s}])$ and the control group $(0.01 \mathrm{~L} / \mathrm{s}[-0.075-0.032 \mathrm{~L} / \mathrm{s}])$ $(P=0.208)$.

\section{Discussion}

The goal of this study was to evaluate the effect of repeated Waon therapy for COPD patients. The changes in VC, PEF,

Table 2 Changes in the 6-minute walk test, at baseline and after 4 weeks

\begin{tabular}{lll}
\hline & $\begin{array}{l}\text { Waon } \\
(\mathbf{n}=10)\end{array}$ & $\begin{array}{l}\text { Control } \\
(\mathbf{n}=10)\end{array}$ \\
\hline $\begin{array}{ll}\text { Maximum Borg scale } \\
\quad \text { At baseline }\end{array}$ & $3.0(1.6-7.0)$ & $3.5(1.8-5.5)$ \\
$\quad$ After 4 weeks & $2.0(0.37-5.0)$ & $2.5(0.9-7.0)$ \\
Walk distance (m) & & \\
$\quad$ At baseline & $287 \pm 131$ & $291 \pm 114$ \\
$\quad$ After 4 weeks & $333 \pm 106$ & $310 \pm 110$ \\
$\begin{array}{l}\text { Minimum SpO } \\
\text { At baseline }\end{array}$ & $88 \pm 5$ & $85 \pm 4$ \\
$\quad$ After 4 weeks & $89 \pm 5$ & $87 \pm 5$ \\
Maximum heart rate (beats/min) & & \\
$\quad$ At baseline & $112 \pm 20$ & $101 \pm 15$ \\
$\quad$ After 4 weeks & $109 \pm 26$ & $107 \pm 15$ \\
\hline
\end{tabular}

Note: Data are presented as means \pm SD or median (25th-75th percentile). Abbreviations: $\mathrm{SD}$, standard deviation; $\mathrm{SpO}_{2}$, oxygen saturation.
Table 3 Change in ventilatory parameters, at baseline and after 4 weeks

\begin{tabular}{|c|c|c|}
\hline & $\begin{array}{l}\text { Waon } \\
(n=10)\end{array}$ & $\begin{array}{l}\text { Control } \\
(n=10)\end{array}$ \\
\hline \multicolumn{3}{|l|}{ PEF (L/s) } \\
\hline At baseline & $3.08 \pm 0.999$ & $3.85 \pm 1.543$ \\
\hline After 4 weeks & $3.56 \pm 1.478$ & $3.73 \pm 1.64$ \\
\hline \multicolumn{3}{|l|}{$\mathrm{FEF}_{50}(\mathrm{~L} / \mathrm{s})$} \\
\hline At baseline & $0.37(0.3 \mathrm{I}-0.7 \mathrm{I})$ & $0.50(0.26-0.82)$ \\
\hline After 4 weeks & $0.52(0.29-0.82)$ & $0.52(0.24-0.77)$ \\
\hline \multicolumn{3}{|l|}{$\mathrm{FEF}_{25}(\mathrm{~L} / \mathrm{s})$} \\
\hline At baseline & $0.17(0.15-0.27)$ & $0.22(0.16-0.3 \mathrm{I})$ \\
\hline After 4 weeks & $0.21(0.12-0.33)$ & $0.22(0.17-0.28)$ \\
\hline \multicolumn{3}{|l|}{ VC (L) } \\
\hline At baseline & $2.87 \pm 0.68$ & $2.90 \pm 0.65$ \\
\hline After 4 weeks & $3.16 \pm 0.69$ & $2.92 \pm 0.63$ \\
\hline \multicolumn{3}{|l|}{ FVC (L) } \\
\hline At baseline & $2.6 \pm 0.764$ & $2.71 \pm 0.936$ \\
\hline After 4 weeks & $2.77 \pm 0.969$ & $2.65 \pm 0.869$ \\
\hline \multicolumn{3}{|l|}{$\mathrm{FEV}_{1}(\mathrm{~L})$} \\
\hline At baseline & $1.22 \pm 0.43$ & $1.34 \pm 0.66$ \\
\hline After 4 weeks & $1.35 \pm 0.56$ & $1.32 \pm 0.644$ \\
\hline
\end{tabular}

Notes: Data are presented as means \pm SD or median (25th-75th percentile).

Abbreviations: SD, standard deviation; PEF, peak expiratory flow; $\mathrm{FEF}_{50}$, forced expiratory flow after $50 \%$ of expired $\mathrm{FVC} ; \mathrm{FEF}_{25}$, forced expiratory flow after $75 \%$ of

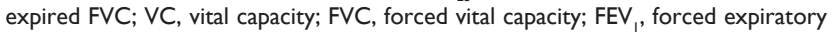
volume in I second; L, Liter; L/s, Liter per second.

and $\mathrm{FEF}_{50}$ in the Waon group were statistically larger than those in the control group. Notably, a significant betweengroup difference was observed in the changes in $\mathrm{FEF}_{50}$. These results indicate that the combination of repeated Waon therapy and conventional therapies may be beneficial for comprehensive COPD treatment, from the aspect of improving airway obstruction, which in turn improves exercise tolerance in patients with COPD.

COPD is characterized by a progressive worsening of airflow limitation, associated with abnormally inflamed airways in older smokers. Leukocytes recruited to the lung contribute to COPD pathology by releasing reactive oxygen metabolites and proteolytic enzyme. ${ }^{17}$ Thus, the larger improvement of $\mathrm{VC}, \mathrm{PEF}$, and $\mathrm{FEF}_{50}$ after repeated Waon therapy in our results was speculated to result from the suppression of airway inflammation and the alleviation of airway obstruction after repeated Waon therapy; the expansibility of lung parenchyma might also be heightened. In 2001, Ikeda et al demonstrated that repeated Waon therapy upregulated arterial eNOS expression in Syrian golden hamsters ${ }^{18}$ and that eNOS expression and nitric oxide (NO) also increased in cardiomyopathic hamsters with heart failure. ${ }^{19}$ In a pilot study of 13 consecutive patients with severe COPD, Umehara et al ${ }^{8}$ found that repeated Waon therapy significantly improved pulmonary hypertension during exercise. They surmised 


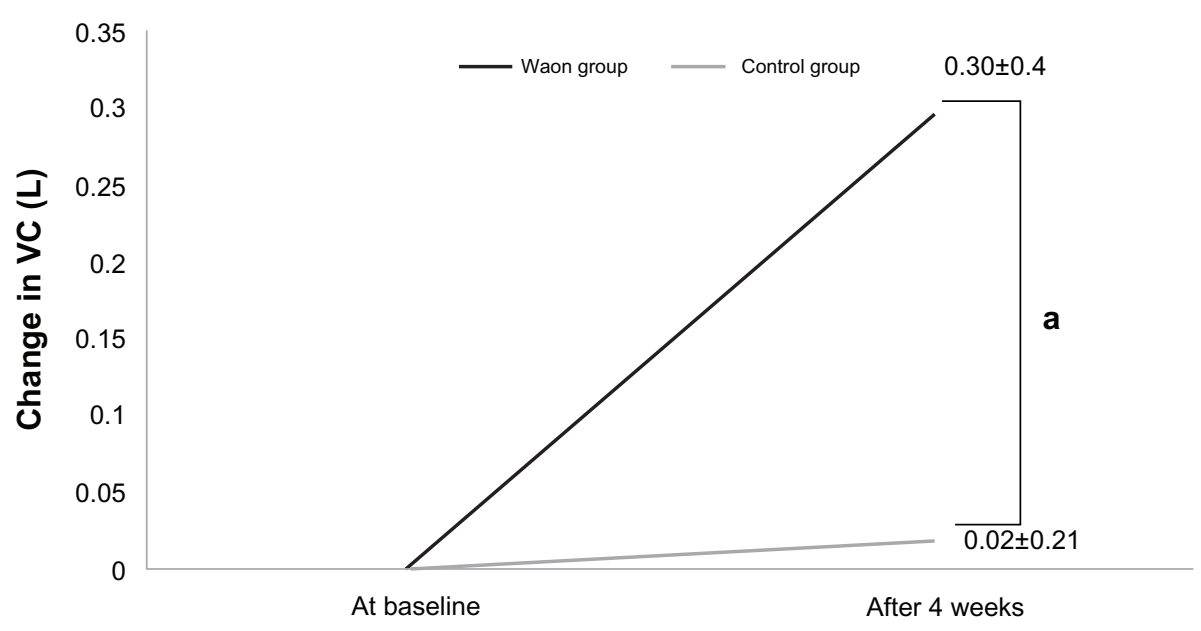

Figure I Amount of change in VC for each patient for the pulmonary function test.

Notes: $P=0.077$ compared with the control, analyzed by unpaired $t$-test. Data are presented as means $\pm S D$.

Abbreviations: SD, standard deviation; VC, vital capacity; L, Liter.

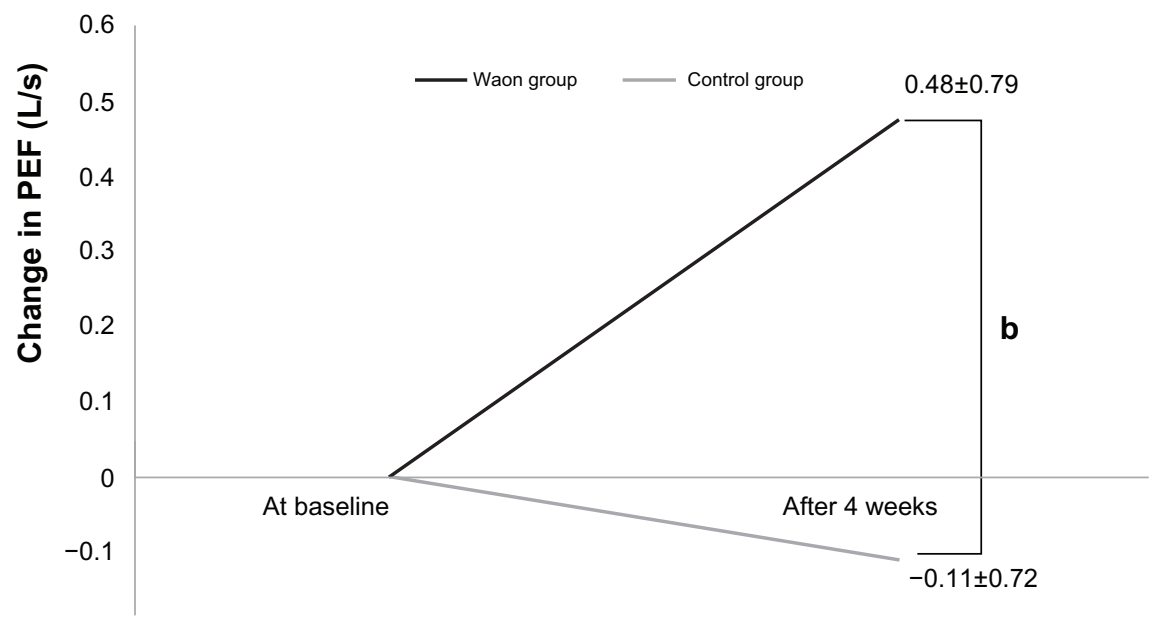

Figure 2 Amount of change in PEF for each patient for the pulmonary function test.

Notes: ${ }^{\mathrm{P}} \mathrm{P}=0.095$ compared with the control, analyzed by unpaired $t$-test. Data are presented as means \pm SD.

Abbreviations: SD, standard deviation; PEF, peak expiratory flow; L/s, Liter per second.

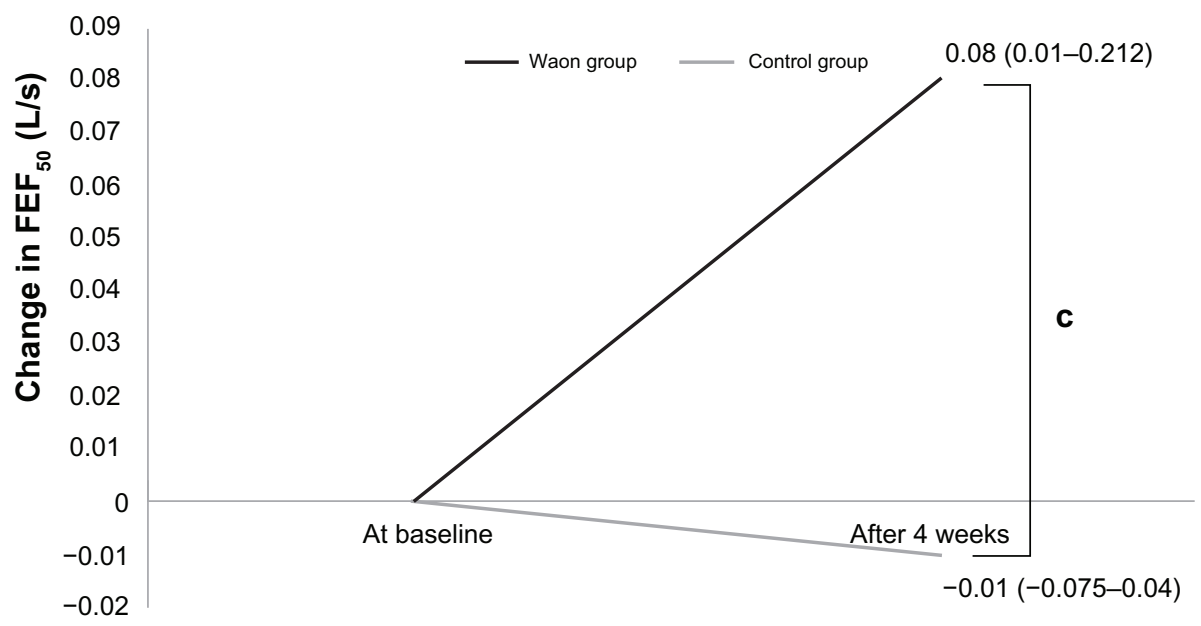

Figure 3 Amount of change in $\mathrm{FEF}_{50}$ for each patient for the pulmonary function test.

Notes: ${ }^{c}=0.019$ compared with control, analyzed by Mann-Whitney test. Data are presented as median (with ranges in parentheses, 25 th-75th percentile). Abbreviations: $\mathrm{FEF}_{50}$, forced expiratory flow after $50 \%$ of expired forced vital capacity; L/s, Liter per second. 
that Waon therapy increased the expression of eNOS in the pulmonary artery and improved pulmonary artery vascular function. However, it is unclear whether repeated Waon therapy influences the level of NO in the airway; it is possible that repeated Waon therapy influences the level of NO in the airway of COPD patients.

Many studies investigating NO and pulmonary function parameters have been reported. Ansarin et al demonstrated that among patients with COPD, exhaled NO was inversely correlated with $\mathrm{FEV}_{1}$, further suggesting a relationship between NO production and bronchoconstriction. ${ }^{20}$ Moreover, Tadié et al reported that nitric oxide synthase 2, one of the isoforms that produces $\mathrm{NO}$, seems to be involved in a constriction response to airway stretch. ${ }^{21}$ Brindicci et al ${ }^{22}$ studied 47 patients with different severities of COPD, as determined by the GOLD guidelines. They found that COPD severity was correlated with an increased steady-state alveolar or peripheral NO concentration regardless of the patient's smoking habit or current treatment. Moreover, McCurdy et al showed that in patients with GOLD stages 3 and 4 COPD, peripheral NO correlated with functional status, and large airway NO parameters correlated with health status. In this study, worsening global health status and increasing subjective symptoms were associated with increasing airway NO flux. ${ }^{23}$ Our study did not evaluate the airway inflammation using NO flux in the airway before and after the program, but from the results of various studies, we speculated that the level of NO in the airway was decreased after repeated Waon therapy and that decreased NO flux influenced the relaxation of airway smooth muscles and alleviated airway obstruction.

The improvement of subjective symptoms is of particular importance in the evaluation of COPD treatment. This study was the first controlled clinical trial to evaluate repeated Waon therapy, using both the 6MWT and pulmonary function test.

The 6-minute walk distance is often intercorrelated with QOL for COPD patients. Mangueira et al found that healthrelated QOL (HRQOL) presented a negative correlation with the 6-minute walk distance and a positive correlation with the sensation of dyspnea and fatigue, as measured by the Borg scale, in a cross-sectional study involving 30 women with COPD. ${ }^{24}$ Umehara et $\mathrm{al}^{8}$ reported in a pilot study, that repeated Waon therapy significantly improved St George's Respiratory Questionnaire scores and prolonged the mean exercise time in the constant load cycle ergometer exercise test, in patients with severe COPD. In contrast, the grades on the Medical Research Council dyspnea scale, which measures dyspnea severity, did not change. ${ }^{25}$ In our controlled clinical trial as well, dyspnea did not show a significant between-group difference as shown in the change in the maximum Borg scale score $(P=0.147)$.

This study did have several limitations. The sample size was small, and an obvious selection bias was present due to the study being nonrandomized and unblinded. Thus, the results in this study evaluating the effect of repeated Waon therapy should only be viewed as preliminary. Further studies are needed to investigate not only exercise tolerance and pulmonary function, but also, the changes in biological markers, such as the NO flux, in order to understand the mechanism of improvement of airway obstruction. The investigation of the changes in NO flux before and after Waon therapy may provide insight into the association between repeated Waon therapy and airflow limitation.

Over the 4-week study period, none of the patients assigned to the study experienced arrhythmias, angina, or respiratory distress during Waon therapy or the conventional therapy. There were no incidences of nontolerance of the therapies.

In conclusion, this study provides new information on the effect of repeated Waon therapy for patients with COPD. The results obtained in this study show that the addition of repeated Waon therapy to conventional therapy for COPD patients could be useful for improving airway obstruction and might reduce dyspnea on exertion.

\section{Acknowledgments}

We would like to thank the staff (clinical technologists, physical therapists, and clinical nurses) at Okayama University Hospital, Misasa Medical Center for their assistance.

\section{Disclosure}

The authors report no conflicts of interest in this work.

\section{References}

1. Lacasse Y, Goldstein R, Lasserson TJ, Martin S. Pulmonary rehabilitation for chronic obstructive pulmonary disease [review]. Cochrane Database Syst Rev. 2006;4:CD003793.

2. Nici L, Donner C, Wouters E, et al; ATS/ERS Pulmonary Rehabilitation Writing Committee. American Thoracic Society/European Respiratory Society statement on pulmonary rehabilitation. Am J Respir Crit Care Med. 2006;173(12):1390-1413.

3. Global Initiative for Chronic Obstructive Lung Disease. Global Strategy for Diagnosis, Management, and Prevention of COPD. Revised 2011. London: Global Initiative for Chronic Obstructive Lung Disease, Inc; 2011. Available from: http://www.goldcopd.org/uploads/users/files/ GOLD_Report_2011_Feb21.pdf. Accessed September 12, 2013.

4. Godoy RF, Teixeira PJ, Becker Júnior B, Michelli M, Godoy DV. Longterm repercussions of a pulmonary rehabilitation program on the indices of anxiety, depression, quality of life and physical performance in patients with COPD. J Bras Pneumol. 2009;35(2):129-136. 
5. Sindhwani G, Verma A, Biswas D, Srivastava M, Rawat J. A pilot study on domiciliary pulmonary rehabilitation programme in the management of severe chronic obstructive pulmonary disease. Singapore Med J. 2011;52(9):689-693.

6. Rae S, White P. Swimming pool-based exercise as pulmonary rehabilitation for COPD patients in primary care: feasibility and acceptability. Prim Care Respir J. 2009;18(2):90-94.

7. Tei C, Horikiri Y, Park JC, et al. Acute hemodynamic improvement by thermal vasodilation in congestive heart failure. Circulation. 1995;91(10):2582-2590.

8. Umehara M, Yamaguchi A, Itakura S, et al. Repeated Waon therapy improves pulmonary hypertension during exercise in patients with severe chronic obstructive pulmonary disease. J Cardiol. 2008;51(2): 106-113.

9. Masuda A, Koga Y, Hattanmaru M, Minagoe S, Tei C. The effects of repeated thermal therapy for patients with chronic pain. Psychother Psychosom. 2005;74(5):288-294.

10. ATS Committee on Proficiency Standards for Clinical Pulmonary Function Laboratories. ATS statement: guidelines for the six-minute walk test. Am J Respir Crit Care Med. 2002;166(1):111-117.

11. Brown CD, Benditt JO, Sciurba FC, et al. Exercise testing in severe emphysema: association with quality of life and lung function. COPD. 2008;5(2):117-124.

12. Elpern EH, Stevens D, Kesten S. Variability in performance of timed walk tests in pulmonary rehabilitation programs. Chest. 2000;118(1):98-105.

13. Gerardi DA, Lovett L, Benoit-Connors ML, Reardon JZ, ZuWallack RL. Variables related to increased mortality following out-patient pulmonary rehabilitation. Eur Respir J. 1996;9(3):431-435.

14. Celli BR, Cote CG, Marin JM, et al. The body-mass index, airflow obstruction, dyspnea, and exercise capacity index in chronic obstructive pulmonary disease. $N$ Engl J Med. 2004;350(10):1005-1012.

15. Lareau SC, ZuWallack R, Carlin B, et al. Pulmonary rehabilitation-1999. Summary of statements of the American Thoracic Society. Am J Respir Crit Care Med. 1999;159: 1666-1682.
16. Borg GA. Psychophysical bases of perceived exertion. Med Sci Sports Exerc. 1982;14(5):377-381.

17. Davis BB, Shen YH, Tancredi DJ, Flores V, Davis RP, Pinkerton KE. Leukocytes are recruited through the bronchial circulation to the lung in a spontaneously hypertensive rat model of COPD. PLoS One. 2012;7(3):e33304.

18. Ikeda Y, Biro S, Kamogawa Y, et al. Repeated thermal therapy upregulates arterial endothelial nitric oxide synthase expression in Syrian golden hamsters. Jpn Circ J. 2001;65(5):434-438.

19. Ikeda Y, Biro S, Kamogawa Y, et al. Repeated sauna therapy increases arterial endothelial nitric oxide synthase expression and nitric oxide production in cardiomyopathic hamsters. Circ J. 2005;69(6): $722-729$.

20. Ansarin K, Chatkin JM, Ferreira IM, Gutierrez CA, Zamel N, Chapman KR. Exhaled nitric oxide in chronic obstructive pulmonary disease: relationship to pulmonary function. Eur Respir J. 2001;17(5): 934-938.

21. Tadié JM, Henno P, Leroy I, et al. Role of nitric oxide synthase/arginase balance in bronchial reactivity in patients with chronic obstructive pulmonary disease. Am J Physiol Lung Cell Mol Physiol. 2008;294(3): L489-L497.

22. Brindicci C, Ito K, Resta O, Pride NB, Barnes PJ, Kharitonov SA Exhaled nitric oxide from lung periphery is increased in COPD. Eur Respir J. 2005;26(1):52-59.

23. McCurdy MR, Sharafkhaneh A, Abdel-Monem H, Rojo J, Tittel FK. Exhaled nitric oxide parameters and functional capacity in chronic obstructive pulmonary disease. J Breath Res. 2011;5(1):016003.

24. Mangueira NM, Viega IL, Mangueira Mde A, Pinheiro AN, Costa Mdo R. Correlation between clinical parameters and health-related quality of life in women with COPD. J Bras Pneumol. 2009;35(3):248-255.

25. Bestall JC, Paul EA, Garrod R, et al. Fretcher CM. Usefulness of the Medical ResearchCouncil (MRC) dyspnoea scale as a measure of disability in patients with chronic obstructive pulmonary disease. Thorax.1999;54(7):581-586.
International Journal of COPD

\section{Publish your work in this journal}

The International Journal of COPD is an international, peer-reviewed journal of therapeutics and pharmacology focusing on concise rapid reporting of clinical studies and reviews in COPD. Special focus is given to the pathophysiological processes underlying the disease, intervention programs, patient focused education, and self management protocols.

\section{Dovepress}

This journal is indexed on PubMed Central, MedLine and CAS. The manuscript management system is completely online and includes a very quick and fair peer-review system, which is all easy to use. Visit http://www.dovepress.com/testimonials.php to read real quotes from published authors. 